\title{
Correlation between Fingernail Length and Pinch Strength Among Collegiate Girls
}

\section{K. Jothi Prasanna ${ }^{1}$, S. Shivani ${ }^{2}$}

Section: Healthcare

Sci. Journal Impact

Factor: $6.1(2018)$

ICV: 90.90 (2018)

(c) (7) (8)

Copyright@IJCRR Nadu, India.
'Assistant Professor, SRM College of Physiotherapy, SRM Institute of Science and Technology, Kattankulathur, Chennai 6o3203, Tamil Nadu, India; '2Student, SRM College of Physiotherapy, SRM Institute of Science and Technology, Kattankulathur, Chennai 6o3203, Tamil

\section{ABSTRACT}

Background: The effective and precise picking up of small objects is assisted by a fingernail. It plays a passive role in increasing the sensory perception at finger pulp. Pinch is a prehension pattern type. To perform a pinch involvement of two or three fingers are required where thumb plays a significant role.

Objective: The study objective was to correlate the fingernail length and pinch strength among collegiate girls.

Methods: The study design was non-experimental, study type is an observational study, the sample size is 100 subjects, college female students who are with fingernail length ranged from $0 \mathrm{~mm}$ to $2 \mathrm{~mm}$ were included. The subjects fingernail is measured using vernier calliper and the pinch strength is measured using pinch gauge.

Results: The result shows that there is a significant negative correlation between pinch strength and fingernail length $(p<0.01)$. Conclusion: This study has concluded that the pinch strength decreases as the fingernail length increases.

Key Words: Fingernail length, Pinch strength, Collegiate girls

\section{INTRODUCTION}

Hand helps a person to participate and perform various activities and occupation needed for daily life. 1 Hand function is done by the action of individual muscles and also by the different movements that take place in the joints. The closing, opening or cupping action of the hand in selected postures such as pinch or hook produces prehension activities.2 Padpad prehension, tip-tip prehension and pad-side prehension are the types of prehension handling2. To perform a pinch, the involvement of two or three fingers is required. During pinch strength, the force exerted by the fingers is measured. Thumb plays a significant role in the contribution of the pinch function of the hand. Palmar (three-point) pinch, lateral (key) pinch and tip pinch are the types of pinches. Tip pinch is a type of pinch which involves thumb and index finger. The tip of the thumb meets the tip of the index finger during tip pinch. Palmar pinch involves thumb, index and middle fingers. Lateral pinch is a type of pinch which involves thumb pad and lateral aspect of index finger.1 Average pinch strength among 20-24 years: 1.Tip pinch: right 11.1 pounds left -10.5 pounds 2 . Lateral pinch: right -17.6 pounds left -16.2 pound 3.Palmar pinch: right -17.2 pounds left -16.3 pounds. ${ }^{3}$ Pinch strength is usually assessed using pinch gauge. 1 Fingernail has a passive role to increase the perception of sensation at the pulp of the fingers when necessary counter-pressure necessary amount counter pressure is contributed for constriction of sensory end organ which is present between fingernail and palmar skin. It helps in effective and precise picking up of small objects. ${ }^{4,5}$

\section{MATERIALS AND METHOD}

Vernier calliper and pinch gauge were used in this study. Informed consent was obtained from the subjects. The subjects were selected based on the inclusion and exclusion criteria. The procedure was clearly explained to each individual. The distance from the groove present at the junction of the proximal nail fold and eponychium to the tip of the fingers is defined as the fingernail length. The length from the fingertip to the fingernail tip is considered as fingernail length and it can be ranged from $0 \mathrm{~mm}$ to $2 \mathrm{~mm}$. The length was measured using Vernier calliper. The subjects were asked to adduct

\section{Corresponding Author:}

K. Jothi Prasanna, Assistant Professor, SRM College of Physiotherapy, SRM Institute of Science and Technology, Kattankulathur, Chennai 603203, Tamil Nadu, India; Email: jothiprk@srmist.edu.in

ISSN: 2231-2196 (Print) ISSN: 0975-5241 (Online)

Received: $30.07 .2020 \quad$ Revised: 02.10 .2020

Accepted: 12.11 .2020

Published: 05.01 .2021 
their shoulders and flex their elbow to 90 degrees and they were seated comfortably. The subjects were informed which of three pinch grip should be performed first. The distal portion of the pinch gauge was held by the subjects to maintain the steadiness. Three consecutive trials of each pinch grip were performed. The subject was given rest in between the trials for accuracy. After each trial, the score of the pinch is recorded. The averages of three scores have been recorded.

\section{RESULTS AND DISCUSSION}

The result shows that there is a significant negative correlation between pinch strength and fingernail length. $(\mathrm{p}<0.01)$. Normally the pinch strength is affected by long nails, infection or fingernail due to any disease, loss of sensation due to any neuropathy and any deformities of hand and fingers caused by trauma, injuries and musculoskeletal disorders. Hence the purpose of this study is to find the correlation between fingernail length and pinch strength. Usually, long fingernails are grown by college girls. So, 100 subjects of college girls were selected to participate and their fingernail length was measured. Subjects with $0-2 \mathrm{~mm}$ of fingernail were included in this study (Figure 1-4). Tip, palmar and lateral pinch strength were measured in these subjects. Tip pinch strength is less when compared with the other two pinches. It is due to the involvement of the tip of fingers which performs the pinch. Palmar pinch strength is less when compared with a lateral pinch as the pulp of the fingers is involved. Lateral pinch strength is more when compared with the other two pinch strength. A finger pad is involved in the performance of the pinch. The result shows a negative correlation between the fingernail length and pinch strength. As the length of the fingernail increases the pinch strength decreases. The table shows that there is a significant negative correlation between the fingernail length and pinch strength $(p<0.01)$. Hence in this study, it is found that there is a negative correlation between the fingernail length and pinch strength where the pinch strength decreases as the length of the fingernail increases (Figure 5-7).

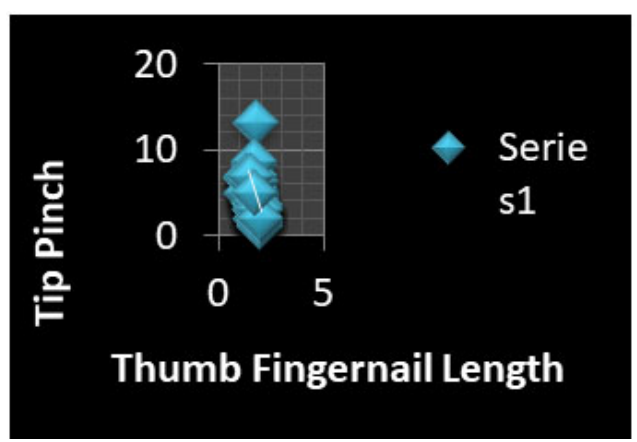

Figure 1: Correlation between thumb fingernail length and the tip pinch.

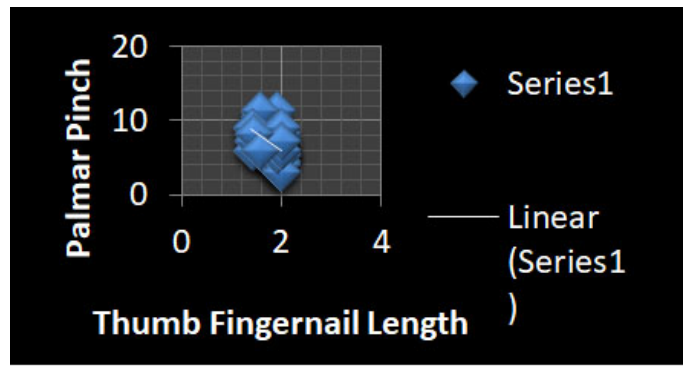

Figure 2: Correlation between thumb fingernail length and the palmar pinch.

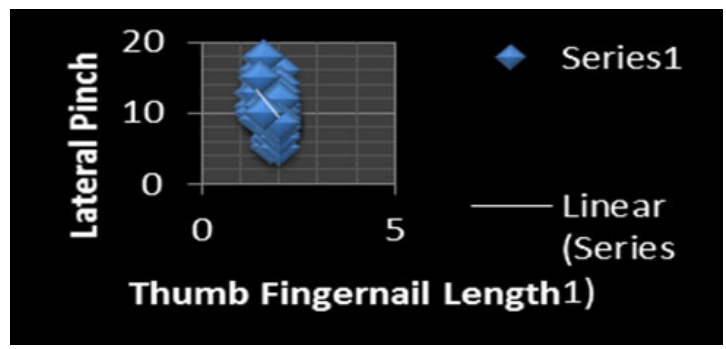

Figure 3: Correlation between thumb fingernail length and the lateral pinch.

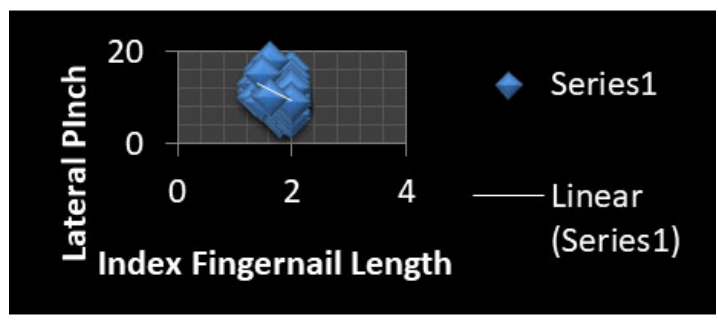

Figure 4: Correlation between thumb fingernail length and the lateral pinch.

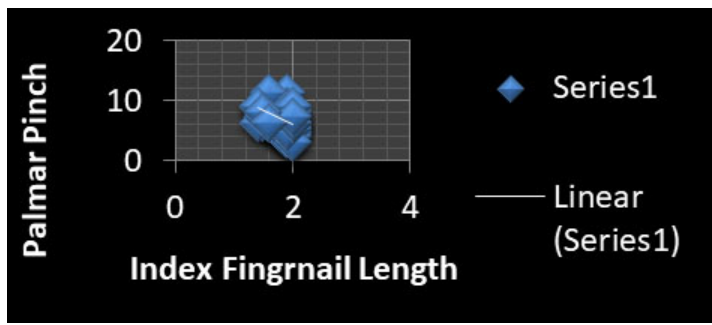

Figure 5: Correlation between index fingernail length and the palmar pinch.

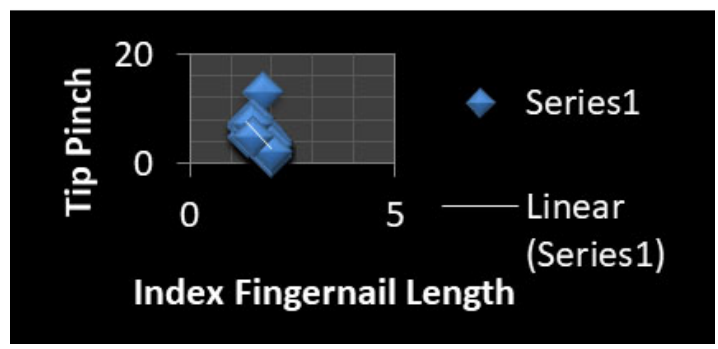

Figure 6: Correlation between index fingernail length and the tip pinch. 


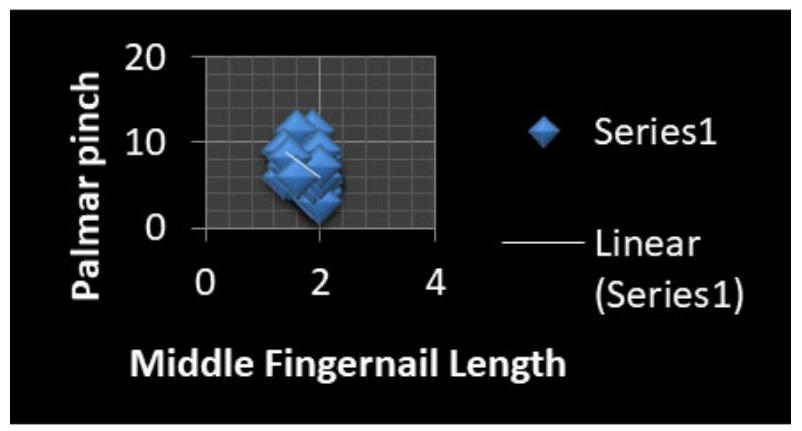

Figure 7: Correlation between index fingernail length and the palmar pinch.

\section{CONCLUSION}

In this study, participants with long fingernail reported to have minimal pinch strength as pinch strength is affected by long nails. Hence, it is concluded that there is a negative correlation between fingernail length and pinch strength

\section{ACKNOWLEDGMENT}

Authors acknowledge the immense help received from the scholars whose articles are cited and included in references to this manuscript. The authors are also grateful to authors / editors / publishers of all those articles, journals, and books from which the literature for this article has been reviewed and discussed.

\section{Conflict of Interest: Nil}

Financial support: Self

\section{REFERENCES}

1. Walukonis K, Beasley J, Boerema R, Powers J, Anderson K. Impact of Finger Position on Pinch Strength. Hand Ther Outcome Meas 2018;23(2):70-76.

2. Napier JR. The prehensile movements of the human hand. The Journal of bone and joint surgery. J Bone Joint Surg $\mathrm{Br}$ 1956Nov;38(4):902-13.

3. Levangie PK, Norkin CC. Joint Structure and function: a comprehensive analysis. 3rd. Philadelphia: FA. Davis Company. 2000.

4. Mathiowetz V, Kashman N, Volland G, Weber K, Dowe M, Rogers S. Grip and pinch strength: normative data for adults. Arch Phys Med Rehabil 1985;66(2):69-74.

5. Shirato R, Abe A, Tsuchiya H, Honda M. Effect of fingernail length on the hand dexterity. J Physic Ther Sci 2017;29(11):1914 9. 